\title{
Brasil y la cuestión americana (Rodó por Sérgio Buarque de Holanda, Gilberto Freyre, José Veríssimo y João Pinto da Silva, 1920-1926)
}

\author{
Pablo Rocca ${ }^{1}$
}

Resumen. Brasil fue un espacio semivacío en la reflexión americana de Rodó, casi un enigma. Sin embargo, en distintos puntos del país-continente, jóvenes que con el tiempo fueron intelectuales decisivos vieron en la obra de Rodó un obstáculo y un desafío. Algunas notas tempranas de los muy jóvenes Sérgio Buarque de Holanda y de Gilberto Freyre revelan sus preocupaciones por las ideas de Rodó en relación a sus propias búsquedas, mientras para el crítico más destacado del Novecientos, José Veríssimo, Ariel se había convertido ya a comienzos de siglo en una posibilidad de diálogo americano y hasta de síntesis de sus ideales profundos, el gaúcho João Pinto da Silva adoptó las ideas del montevideano casi como una guía. Este artículo revisa qué pudo llevar, sobre todo entre 1920 y 1926, a tales escrutinios y posiciones, y cuáles fueron algunos de sus efectos en la escritura y el pensamiento que enlaza Brasil con Hispanoamérica, territorios físicos, lingüísticos y simbólicos de siempre compleja articulación.

Palabras clave: José Enrique Rodó; Brasil; América.

[en] Brazil and the American issue (Rodó por Sérgio Buarque de Holanda, Gilberto Freyre, José Veríssimo y João Pinto da Silva, 1920-1926)

\begin{abstract}
Brazil was a half-empty space in Rodó's American reflection, almost an enigma. However, in different parts of the country-continent, young people who over time were decisive intellectuals saw in Rodó's work an obstacle and a challenge. Some early notes from the very young Sérgio Buarque of Holland and Gilberto Freyre reveal their concerns about Rodó's ideas in relation to his own research, while for the most prominent critic of the Nineteenth Century, José Veríssimo, Ariel had already become, at the beginning of the century, a possibility for American dialogue and even for the synthesis of his deep ideals, the gaúcho João Pinto da Silva adopted the ideas of the Mon This article reviews what could lead, especially between 1920 and 1926, to such scrutinies and positions, and what were some of their effects on writing and thought that links Brazil with Latin America, physical, linguistic and symbolic territories of always complex articulation.
\end{abstract}

Keywords: José Enrique Rodó; Brazil; America.

Sumario. 1. Cosmopolita, regional, ¿nacional? 2. Tres modos de leer.

Cómo citar: Rocca, P. (2017) Brasil y la cuestión americana (Rodó por Sérgio Buarque de Holanda, Gilberto Freyre, José Veríssimo y João Pinto da Silva, 1920-1926), en Anales de Literatura Hispanoamericana 46, 201-210.

1 Universidad de la República, Uruguay.

E-mail: pabloroccapesce@gmail.com 


\section{Cosmopolita, regional, ¿nacional?}

Nunca una obra de pensamiento producida en América Latina tuvo la resonancia de Ariel. En género análogo, y no es casualidad, sólo había conseguido eco semejante Facundo. Civilización o barbarie, de Domingo F. Sarmiento, publicado por entregas en 1845 en Santiago de Chile y reproducido, de inmediato, en El Nacional de Montevideo por sus primeros grandes admiradores (Andrés Lamas, Miguel Cané, etc.), los siempre grandes admirados por José Enrique Rodó, uno de sus primeros exégetas. ${ }^{2}$ El Facundo, a su vez, parece haber sido una de las bases interpretativas - una de las pocas de origen americano- para el brutal conflicto de las culturas según la mirada de Euclides da Cunha en Os sertões (1899/1902), uno de los pocos textos brasileños que Rodó tuvo en su biblioteca personal a partir de 1911, como consta en su imperfecto registro depositado en el Museo Histórico Nacional. ${ }^{3}$ Una referencia al texto de Euclides da Cunha, cuya extensa primera parte debió atribularlo, comparece en un discurso que Rodó dejó en borrador, en el que alcanzó a anotar, con todo, un firme elogio de vaga idea sobre la persona y la obra de su coetáneo. En rigor, esa apología no revela conocimiento preciso alguno de esta última, sino más bien de la abrupta circunstancia patética en que murió Euclides en 1909 y que debió haber impresionado mucho al misantrópico Rodó. ${ }^{4}$ De ese texto que preparó para decir en oportunidad que nunca llegó se conservan unos legibles y valiosos apuntes preliminares, inexplicablemente omitidos en las Obras completas a cargo de Emir Rodríguez Monegal:

[...] hemos seguido desde estos últimos ([tiempos]) ([épocas)] (tiempos), que para citar un nombre solo, un nombre que evoca, (al par) ([al mismo tiempo]) admiración profunda y $([\ldots . . . . .]$.$) tristísima piedad -resumiré en el nombre$ glorioso de Euclydes da Cunha- (el estilista, el pensador)- muerto en la más prometedora madurez de su espíritu - grande en la realidad de su obra, grande en el recuerdo pero (que) quizá (sea) más grande todavía en la esperanza q'en la realidad y que en el recuerdo! (Rodó, 1949: 37-38). ${ }^{5}$

Cuesta medir la autoridad y la presencia fuera de sus circuitos más inmediatos del Facundo, de Os Sertões, de Ariel o cualesquiera obras latinoamericanas dada la trabajosa circulación de los impresos durante el siglo XIX y parte de la centuria

2 Son muchas las referencias en distintos artículos y conferencias, pero el trabajo fundamental de Rodó sobre "la tradición intelectual de Mayo", en el que refunde aportes propios previos, es "Juan María Gutiérrez y su época" (El mirador de Próspero, 1913).

3 "Euclydes da Cunha. Os Sertões./ Ao eminente escriptor José Enrique Rodó offerece, com o mais subido apreço. Domingo de Castro -Abril de 1911". Otro libro brasileño registrado em este catálogo es las Poesias completas, de Machado de Assis, en la edición original de 1901 (Rodó, Catálogo...).

4 Sobre las circunstancias de la muerte del escritor brasileño véase la notable aunque inconclusa biografía Euclides da Cunha. Esboço biográfico, Roberto Ventura. São Paulo, Companhia das Letras, 2002. (Organização Mario Cesar Carvalho e José Carlos Barreto de Santana).Una esmerada edición: Os sertões. Campanha de Canudos, Euclides da Cunha. São Paulo, Atelié Editorial/ Arquivo do Estado/ Imprena Oficial, 2002 (Edição, prefácio, cronología, notas e índices de Leopoldo M. Bernucci).

5 El discurso iba a ser leído en Rio de Janeiro en 1910, adonde nunca fue y, por lo tanto, nunca se pronunció. Este discurso, que Rodríguez Monegal conocía muy bien ya que lo cita en la bibliografía a través de su editor y no de su autor, es una de las tantas omisiones de la por lo demás fundamental edición preparada por Monegal en 1957 y reeditada, con ampliaciones y enmiendas, en 1967. 
subsiguiente. Sea como fuere, al margen de estas zozobras algo más que la fama aproxima al Facundo con Ariel y, en su comunidad fundamental de propósitos, algo más los engarza con Os sertões, cuya segunda parte ("A luta") relata el choque entre las fuerzas del nuevo orden republicano y positivista con los ignorados sertanejos conducidos por un asombroso predicador para la visión europeizada de la ciudad, como inverosímiles (o repelentes) eran los caudillos rurales para las élites rioplatenses. Las ideas fundamentales de Ariel y la cosmovisión de su autor, como lo propuso Real de Azúa en varios de sus trabajos, se fraguan en la tradición intelectual que se remonta a la generación de Mayo, victoriosa en una de aquellas ciudades "cuyo nombre fue un glorioso símbolo en América; que tuvieron a Moreno, a Rivadavia, a Sarmiento; que llevaron la iniciativa de una inmortal Revolución", según enseña Próspero en la parte final de su alocución. Otras trazas de continuidad de un mismo código afloran en el uso del término desierto en cuanto sinónimo de extensiones yermas de la mano fecunda del hombre blanco, algo que se nota en una cita crucial de Juan Bautista Alberdi, cuyo nombre omite: "Ha tiempo que la suprema necesidad de colmar el vacio moral del desierto, hizo decir a un publicista ilustre que, en América, gobernar es poblar". Pero, y hay que remarcarlo, en Ariel dominan los escritores, filósofos e historiadores, sobre todo franceses e ingleses, en especial del universo romántico o positivista. En suma, fuera del archivo argentino y de una rápida mención a "las crónicas heroicas de los conquistadores", América no tiene su propia y autorizada voz en el folleto rodoniano. En este sentido poco había cambiado desde el Facundo, posible génesis de lo que podría denominarse un pensar actuando al que Rodó fue fiel hasta que salió para siempre de Montevideo.

Si estos y tal vez otros americanos se refugian en el subtexto de Ariel es porque Rodó transfiere a la voz del maestro Próspero un objetivo principal, de arduo y delicado cumplimiento: sortear al máximo toda adherencia política inmediata. Eso explicaría la ausencia de palabras en Ariel -no en otros textos- habituales en Facundo y en otros textos coetáneos, como "caudillo" y "montonera", lo que sugiere una calculada distancia de cualquier intento de que el folleto fuera leído como una manifestación de militancia circunstancial y localizada, que estaba empezando a avanzar en la escritura latinoamericana, también en Brasil. Además de esta prevención, que evita hasta su último límite, arrebata a Rodó la ansiedad algo provinciana de quien desea ver el mundo desde las márgenes del Plata y hacer sentir su voz mucho más lejos de ese espacio próspero, bien que aún en ciernes. Para eso necesita sortear lo contingente y, para ser admitido entre sus pares de donde fuere, debe pronunciar las palabras clave de las lecturas modernas. Ariel se nutre de algunas fuentes europeas que ya estaban en Facundo: la ideología liberal que repudia a la multitud y sus conductores; el destino nacional fundado en la creencia de la educación, las letras y la superación individual; la confianza en que América Latina se moderniza en el conocimiento de la escritura metropolitana; la oposición entre inteligencia y vulgaridad como formulación "más alta" de la dicotomía civilización y barbarie, que es apenas una forma más atildada de decir lo mismo.

Para 1900 una sólida trama de letrados hispanoamericanos comenzaron a reforzar sus lazos, seguros de que la literatura de imaginación y pensamiento tenía un centro (París), al que vanamente trataban de acercarse y donde una y otra vez 
eran ignorados. De ahí que leer al colega de la misma lengua era más una cuestión de supervivencia que de cortesía, que no podía sino canalizarse hacia un esfuerzo de conciliación de lo nacional-estatal con lo americano y lo ibérico con las ideas y las letras, vinieran de donde fuere. Nacionalismo y americanismo pueden conjugarse con cosmopolitismo e internacionalismo en los textos de marcada orientación socialista de la que Ariel está exento por completo. El texto de Rodó presenta cuatro ocurrencias del término cosmopolita (etimológicamente: ciudadano); tres de ellas con una inflexión negativa. En el primer caso se remite a "la afluencia inmigratoria", que pone en peligro "nuestras democracias por la incesante agregación de una enorme multitud cosmopolita", que se degenera en los Estados Unidos, "donde la confusión cosmopolita y el atomismo de una mal entendida democracia impiden la formación de una verdadera conciencia nacional". A ese mal lo agrava el "utilitarismo, vacio de todo contenido ideal, la vaguedad cosmopolita, y la nivelación de la democracia bastarda". En el análisis de estas dos últimas citas, Nöel Salomon detecta un punto neurálgico en el ataque a la credibilidad de la democracia en Estados Unidos, y en el empleo del vocablo adivina su recelo ante el flujo migratorio que llegaba sin cesar al Río de la Plata (Salomon, 1986). Pero Ariel provee un cuarto y muy halagüeño sentido de la palabra que escapó al cuidado del investigador:

El cosmopolitismo, que hemos de acatar como una irresistible necesidad de nuestra formación, no excluye, ni ese sentimiento de fidelidad a lo pasado, ni la fuerza directriz y plasmante con que debe el genio de la raza imponerse en la refundición de los elementos que constituirán al americano definitivo del futuro.

En este sentido, el cosmopolitismo aparece como la provechosa incidencia de la cultura universal en la cultura nativa; brota como hecho verificable mientras el ser "americano definitivo" no pasa de una riesgosa apuesta condicionada por la casi infranqueable barrera del gran vecino lusohablante. Devuelto a su experiencia local, Rodó sabe bien que el problema viene de lejos y que era una cuestión vital para la literatura de las dos grandes lenguas europeas que dominaban en América. En 1869 el joven Machado de Assis apuntó con clarividencia que los "poetas da América espanhola são pouco conhecidos entre nós, do mesmo modo que os nossos são pouco conhecidos nas repúblicas do continente. Grande e recíproca vantagem seria, se houvesse relações intimas entre as duas literaturas" (Machado de Assis, 2003: 368 [19/IX/1869]). Casi en los mismos términos que Machado de Assis se pronunciará Rodó cuarenta años después en los borradores del frustrado discurso de 1910, preparado para un auditorio brasileño:

Nos conocemos intelectualmente muy poco. Los libros europeos, pasando de un nivel mediano de valer científico ó artístico, llegan á ser en breve tiempo tan familiares para vosotros como para nosotros. En cambio, los mejores libros hispano-americanos, son, (en general) tan desconocidos ([en]) (para) el Brasil, como ([en]) (para) la América Española son desconocidos los mejores libros brasileños. [...] Nuestro conocimiento mútuo no será completo, ni llegará á lo esencial, mientras no nos conozcamos también por nuestros libros". (Rodó, 1949: 38). 
Todo aquel que mencionara esa vecindad señalaría, entonces y hasta ahora las imposibilidades de ese diálogo. Uno de los críticos literarios más activos e importantes en el cruce de los siglos, José Veríssimo (1857-1916), que había nacido catorce años antes que Rodó y murió un año antes que él, animado por el deseo de modernizar a Brasil integrándolo al movimiento central de la cultura, advirtió que era menester acercarse a la ignorada Hispanoamérica para movilizar el consabido conocimiento recíproco y para entablar un proyecto político que contrarrestrara la fuerza avasallante de los Estados Unidos, que tenía sus muchos y potentes admiradores en Brasil. Uno de los más importantes, su frecuente contendor Manuel de Oliveira Lima, en su libro Nos Estados Unidos, impressões políticas e sociais, publicado en 1899 -es decir, a meses de la aparición de Arielpresenta para Veríssimo un "excesso de otimismo e de benevolência [sobre] a profunda e larga corrupção da política e da administração americanas" (Verissimo, 2003: 151). Aunque, como se ve, con un discurso más incisivo -que ejercerá en tantos otros artículos sobre el tema y a menudo contra el mismo Oliveira Lima-, Veríssimo fue presa del positivismo y por lo tanto creyó en la existencia de las razas superiores e inferiores, en pueblos débiles y fuertes, en que el mestizaje no conducía a nada demasiado bueno. Quizá precisamente por eso pudo celebrar en Ariel la prosperidad de ideales clásicos y de ostensible matriz europea injertados en un hipotético cuerpo del pensar americano más que en su concreta materialidad social. Verissimo fue el primer brasileño que leyó con cuidado Ariel. Según el gran exégeta del crítico brasileño, João Alexandre Barbosa, ya el 18 de diciembre de 1900 en Jornal do Comércio, de Rio de Janeiro, apareció una primera versión de "A regeneração da América Latina" (Barbosa en Veríssimo, 1986: 9), artículo en el que comenta dos libros editados en el Río de la Plata, el del gallego-argentino Antonio Rodríguez del Busto, Peligros americanos, publicado en Córdoba en 1899 y Ariel, al que glosa y traduce - por cierto muy bien- extensamente. De su título dice que en lugar de haber optado por ese tan "enigmático de fantasía artística, poderia levar o que dei a esse artigo" (Verissimo, 2003: 251). En otras palabras, a diferencia del hispano-argentino Rodríguez del Busto o del más elocuente Martí o de los brasileños Manuel Bonfim u Oliveira Viana o el propio crítico, Rodó esquiva el objeto preciso transformando en una crítica algo abstracta a los Estados Unidos, lo que Veríssimo entiende que debe ser manifestado como fuerte contrapunto de ese "sentimento latino". Y aun así tal vez la formula mejor que nadie, ya que desde sus valores se podría regenerar a América Latina, según la autoparáfrasis. Algo más los enlaza: la admiración por el franco-argentino Paul Groussac, quien en discursos públicos y en su libro de viaje Del Plata al Niágara (1897) ofreció una imagen descorazonadora de la vida en los Estados Unidos. Leyendo a Groussac, el joven Rodó pudo obtener imágenes que alimentaran su desazón por ese país que admiraba, "pero no los amo". Lo mismo, o casi, pudo decir Veríssimo, como ya lo anotó Barbosa, y la fuente pudo ser la misma, ese Groussac al que Borges admirará tanto que lo propondrá como su espejo en el "Poema de los dones", ese Groussac que "dos que conheço, talvez [sea] o único escritor da história política americana que se faça ler com aprezimento" (Verissimo, 2003: 365). De paso: qué mejor desafío y provocación que situar como a quien mejor escribe en español en América a un francés transterrado. 
La voz del inquieto e informadísimo crítico brasileño, miembro central de la Academia brasileira de letras, autor de una renovada História da literatura brasileira que dejó pronta cuando lo encontró la muerte, pudo no ser desoída entre quienes se estaban formando cuando en 1916 apareció ese libro fundamental. Para esos jóvenes Ariel y otros textos de Rodó sirvieron -a favor o en contra- en clave nacional o con destino a su reformulación.

\section{Tres modos de leer}

Además del lúcido Veríssimo, ese híbrido retórico que es Ariel (alegato, discurso, narración, ensayo) dejó una huella considerable en tres dispares figuras del Brasil intelectual en la década del veinte: un intelectual de provincia y del sur (João Pinto da Silva); un adolescente paulista que será una de las figuras clave para la discusión de su país desde fines de los años treinta (Sérgio Buarque de Holanda) y el próximo fundador de la antropología cultural en el país que disputa al anterior la construcción de otra imagen de Brasil en los mismos años (Gilberto Freyre). Todos leyeron a Rodó en castellano, mucho antes de que saliera la primera traducción al portugués de Ariel. $^{6}$

En 1920 Sérgio Buarque de Holanda (1902-1982) escribió su segundo artículo en la prestigiosa Revista do Brasil. Tenía dieciocho años. Buarque se ocupó de Ariel, en base a la edición madrileña aparecida el año anterior y como Veríssimo y tantos otros lectores futuros, se concentró en la quinta parte del discurso de Próspero, la que se ocupa de los Estados Unidos. Rodó había escrito: "En sociabilidad, como en literatura, como en arte, la imitación inconsulta no hará nunca sino deformar las líneas del modelo". Su joven crítico baraja esta postulación para defender la existencia de caracteres nacionales en contraposición a los caracteres exóticos a los anteriores. Lo anterior desemboca en la contraposición entre la "cultura dos Estados Unidos" y la de América Latina, un asunto que, como vimos, tenía un tránsito fluido y una polémica larga en Brasil. Pero, sorprendentemente, parece dar por cerrada la idea de una cultura estadounidense, como si no estuviera sometida a ninguna presión de cambio y, en su lugar, entiende como un proceso a "essa sociedade em formação que se chama: o povo brasileiro". Buarque de Holanda piensa que las élites, afanadas en un fervor imitativo que las hace ignorar su propio suelo y su cultura, han bloqueado la afirmación de ese proceso. De esa manera ve a Brasil como un acto inconcluso de creación y a EE.UU. como un molde seguro, en el que se fraguó una forma de la representatividad social. Ese modelo, sin embargo, no puede importarse y en ese empeño imitativo está el error fatal de la élite brasileña.

Como Veríssimo, como otros antes, Sérgio Buarque de Holanda advierte el nocivo efecto del utilitarismo, tan condenado por Rodó, comprobación que lo lleva a crear otra antinomia inspirada en Ariel que funciona por desplazamiento: el

6 Ariel, José Enrique Rodó. Rio de Janeiro, Editora Renascença, 1933. (Tradução de Hermes da Fonseca). Esta es la primera traducción al portugués de que tenemos noticia, gracias a la Bibliografía de José Enrique Rodó, Arturo Scarone. Montevideo, 1930. Como se aclara más adelante, Pinto da Silva, nacido en la frontera con Uruguay, tomó contacto con ediciones uruguayas de Ariel, Motivos de Proteo y El mirador de Próspero, esta última enviada por el propio autor. 
pueblo yanqui sería utilitario mientras el brasileño manifestaría la negación de todo propósito material último, no porque represente la esencia de los valores de la cultura clásica - como quiere Rodó para los hispanoamericanos-, sino porque se acerca a la naturaleza, "o caminho que [...] nos conduzirá a Ariel, sempre mais nobre e mais digno do que Calibán" (Buarque de Holanda, 1996: 45). Tres lustros más tarde, en 1936, ya despojado del impulso juvenil e idealista, ya mejor organizado en su capacidad argumentativa publicará Raízes do Brasil, uno de los ensayos fundamentales del siglo XX en su país y por esa época, junto a Casa Grande \& Senzala, de Gilberto Freyre (1933), la interpretación más aguda e influyente de la sociedad y la cultura brasileñas. Podría postularse que la idea del carácter brasileño como expresión natural, que está en el artículo del adolescente seducido por la prosa de Rodó, resurja años después en la célebre metáfora de la "cordialidade" de Raizes do Brasil como gran contribución universal del pueblo brasileño a la empresa humana de conocimiento y contacto. Ya Pedro Meira Monteiro observó otra correspondencia inversamente proporcional que proviene de un artículo de Rodó titulado "Iberoamérica", de 1910, en el que se defiende la "unidad intima" del iberoamericanismo (Rodó, 1967: 687), mientras que Raizes do Brasil propone que "o americano ainda é interiormente inexistente" (Meira Monteiro, 2009: 169). Visto así, el diálogo se habría prolongado mucho más de lo previsto con el perfume de la prosa de Rodó.

Con dieciocho años de edad, igual que su colega, Gilberto Freyre (1900-1987) comenzó a escribir una serie de notas breves para el Diário de Pernambuco, en su natal Recife. Esos artículos, precozmente eruditos y altaneros, apuntan el rumbo del grande y polémico ensayista. En 1923 Freyre parece haber descubierto la literatura de Rodó y, en ella, parece haber hallado un molesto obstáculo. En la primera ocasión en que cita al escritor uruguayo lo hace en una reflexión sobre la alta cultura. Al final de la nota menciona al crítico portugués Fidelino de Figueiredo "no seu estudo sobre Rodó", resume sus ideas -que son en sustancia las mismas que las del uruguayo-, acordando en que "o caminho será, não destruir essa democracia como Renan aconselhava [sino] salvar a democracia, educando$a$ ". Mas claramente antipática $-\mathrm{y}$ tal vez acertada- es la segunda referencia en que Rodó se le aparece a Freyre como un imitador de tercer grado: "Walter Pater repete de Bacon, e creio que de Pater, [repete] Rodó, que não há refinada beleza sem alguma coisa de estranho nas suas proporções" (Freyre, 2016: 238) [22/4/1923]). Igualmente distante es la última mención que personifica en el autor de Ariel a los ingenuos predicadores de la cultura de élite. ${ }^{7}$ Estos trazos sueltos del conocimiento de una obra, que para el joven crítico se reducía a Ariel y a los ensayos de El mirador de Próspero (1913), eran suficientes para apartarse de ella. Quien, como el joven Freyre, estaba comenzando a pensar la escritura integrada a otras proyecciones más radicadas en lo cultural, un pensamiento que -puede intuirse en las pequeñas citas mencionadas- percibía profundamente desamericanizado y desasido no podía sino resultarle extraño y hasta contraproducente. Si Sérgio Buarque pudo seguir dialogando en secreto con su primera lectura de Ariel, el Freyre maduro ignorará soberanamente esta obra en

"Soube o Fradique, de Eça [de Queiróz] antecipar a insuficiência dessa ilusão o em que todos os Rodós deixaram s'embaler. Fradique queria por a Ciência uma espécie de sacro colégio intelectual. Que vem a ser isso senão o ideal duma cultura de elite?" (Freyre, 2016: 290 [Nota del 9/IX/1923]. 
varios ensayos sobre la cuestión americana, en particular en uno que elaboró -nada menos- que entre 1963 y 1966, cuando el tema había adquirido su mayor temperatura después del triunfo de la Revolución cubana, un ensayo que finalmente tituló "Americanidade, latinidade e tropicalidade". En esta pieza tan esmeradamente construida comparte con las reflexiones que Ezequiel Martínez Estrada venía proponiendo desde mediados de la década del treinta con Radiografia de la Pampa la recusación de todos aquellos que permanecieron ciegos al "gaúcho ou ameríndio ou negro nas raizes de qualquer cultura latinoamericana", para concluir que esos sujetos son los que pautan la "condição absoluta de autenticidade para essas culturas" (Freyre, 2003: 25 [1966]). La lista de rechazados incluye a Alberdi, Echeverría y Sarmiento. El fantasma de Rodó planea ahora, para mejor borrarlo.

El último de los lectores brasileños de la primera hora, hasta donde tenemos noticia, en verdad fue el segundo. João Pinto da Silva (1889-1950) no era tan joven como los precedentes ni será tan decisivo para la configuración posterior de imágenes del Brasil, su historia y su cultura como Buarque o Freyre, a quienes llevaba más de diez años de edad. Originario de la frontera, nacido a orillas del Yaguarón, ese "rio de turvas aguas lentas" (Pinto da Silva, 1926: 5), que baña la frontera de los dos países, que se sepa Pinto da Silva fue el único exégeta y apologista rodoniano de Brasil que llegó a tener correspondencia con el autor. Llegó, incluso, a enviarle dos artículos sobre sus obras, en apariencia los primeros que se escribieron en Brasil sobre Rodó, que este supo comentar con interés en otras dos cartas a su corresponsal. Al cabo, Pinto da Silva dedicó un capítulo reverencial al Maestro en su libro Vultos do meu caminho, publicado en Porto Alegre, en 1926, cuando esta ciudad aún era periférica para los debates del pensamiento brasileño. ${ }^{8}$

Alentado porque Pinto da Silva percibe en su obra un "comunicativo sentimento de fraternidade continental', una vez más Rodó apuesta por la literatura como vía de profundo conocimiento humano. En su estilo profético dice a su corresponsal y crítico que los "estudios paralelos de ambas literaturas [la de Brasil y la de Hispanoamérica] merecen proseguirse, para demostrar sus grandes afinidades y propender a su recíproco conocimiento" (Rodó, 1967: 1.475). Sin saberlo, Rodó estaba dando una clave interpretativa que los brasileños leyeron (y leerán) en Ariel $\mathrm{y}$ en otros de sus textos, ya sea con unción, ya con incomodidad o molestia. $\mathrm{Su}$ obra había contribuido al regreso triunfal del hispanismo, tan ácidamente criticado durante el siglo XIX en el Río de la Plata, y de esa forma, como si trazara una rara parábola, la apelación a la colectividad ibera permitía a los enclaustrados jóvenes brasileños rescatar críticamente la otra forma del iberoamericanismo, la de la lengua portuguesa, ahora sin necesidad de una mediación impuesta por la antigua y decadente metrópoli. Como arrastre de esa vindicación posible, con la pequeña ayuda de Rodó se podía apreciar mejor el lugar presente y futuro de Brasil, su aporte al pensamiento y la literatura americana y de donde sea.

8 Debo a la generosidad de la $\operatorname{Prof}^{\mathrm{a}} \operatorname{Dr}^{\mathrm{a}}$ María Eunice Moreira copia del libro de Pinto da Silva. 


\section{Referencias bibliográficas}

Ardao, Arturo, "Del Calibán de Renan al Calibán de Rodó", en Estudios latinoamericanos de historia de las ideas. Caracas: Monte Avila Editores, 1978, pp. 141-168. [1971].

Buarque de Holanda, Sérgio, "Ariel”, en Rafael Arnoni Prado comp. y pról. O espíritu e a letra. Estudos de crítica literária. São Paulo: Companhia das Letras, 1996, pp. 42-46. [Originalmente en Revista do Brasil, 1920].

—Raízes do Brasil. São Paulo: Companhia das Letras, 2002. Prefácio de Antonio Candido. [1936].

Freyre, Gilberto, “1”, en José Antônio Gonsalves de Mello (organização), Geneton Moraes Neto (apresentação), Nilo Pereira (prefácio), Edson Nery da Fonseca (biobibliografia), Gustavo Henrique Tuna (índice onomástico). Tempo de aprendiz. Artigos publicados em jornais na adolescência e na primeira mocidade do autor (1918-1926). São Paulo: Global, 2016, pp. 237-240. [Originalmente en Diário de Pernambuco, 1923].

- “21", en José Antônio Gonsalves de Mello (organização), Geneton Moraes Neto (apresentação), Nilo Pereira (prefácio), Edson Nery da Fonseca (biobibliografia), Gustavo Henrique Tuna (índice onomástico). Tempo de aprendiz. Artigos publicados em jornais na adolescência e na primeira mocidade do autor (1918-1926). São Paulo: Global, 2016. [Originalmente en Diário de Pernambuco, 1923].

- Americanidade e Latinidade da América Latina e outros textos afins. Organização e notas de Edson Nery da Fonseca, prefácio de Enrique Rodríguez Larreta e Guillermo Giucci. São Paulo: Impresora Oficial do Estado/ Universidade de Brasília, 2003.

Machado de Assis. Crítica literária e textos diversos. Organização de Sílvia Maria Azevedo, Adriana Dusilek e Daniela Mantarro Callipo. São Paulo: Ed. UNESP, 2013.

Meira Monteiro, Pedro e João Kennedy Eugênio (eds.). Sérgio Buarque de Holanda. Perspectivas. Campinas, SP/ Rio de Janeiro, RJ: Editora Unicamp/Editora Eduerj, 2008.

Meira Monteiro, Pedro, “As Raízes do Brasil no espelho de Próspero", Novos Estudos, n. ${ }^{\circ}$ 83 (março 2009), pp. 159-173.

Pinto da Silva, João, "José Enrique Rodó", en Vultos do meu caminho. Porto Alegre: Ed. Globo, 1926, pp. 5-41.

Real de Azúa, Carlos, "El problema de la valoración de Rodó", en Historia visible e historia esotérica. Personajes y claves del debate latinoamericano. Montevideo: Arca/Calicanto, 1975: 137-156. [1967]

— “Ariel, libro porteño", en Historia visible e historia esotérica. Personajes y claves del debate latinoamericano. Montevideo: Arca/Calicanto, 1975, pp. 157-173. [1971].

-Prólogo a Motivos de Proteo, en Ariel/Motivos de Proteo. Caracas: Biblioteca Ayacucho, 1975.

Rodó, José Enrique. Obras Completas. Editadas con intr., pról. y notas por Emir Rodríguez Monegal. Madrid: Aguilar, 1967 (2 $2^{\mathrm{a}}$ ed. aumentada y corregida). [Textos citados: Ariel, "Iberoamericanismo"].

— “Un discurso de Rodó sobre el Brasil", Revista del INIAL (1949). Presentación y notas de José Enrique Etcheverry, pp. 36- 37.

- [Inventario de su biblioteca personal]. Tomo 3.981, Museo Histórico Nacional, Montevideo.

Salomon, Noël, "Cosmopolitismo e internacionalismo (Desde 1880 hasta 1940)", en América Latina en sus ideas. Leopoldo Zea coord. e intr. general. México: Siglo XXI, 1986, pp. 172-200.

Veríssimo, José. Cultura, literatura e políca na América Latina. São Paulo: Editora Brasiliense, 1986. (Seleção e apresentação de João Alexandre Barbosa). [Texto citado: "América latina e América inglesa"].

-Homens e coisas estrangeiras, 1899-1908. São Paulo: Academia Brasileira de Letras/ Topbooks, 2003. (Prefácio de João Alexandre Barbosa). [1902, 1905, 1910]. [Textos 
citados: "O país extraordinário", "A regenerão da América Latina”, "Um retrato de Rosas"]. 